\title{
Análise retrospectiva de casos de maus tratos contra cães e gatos na cidade de São Paulo
}

\author{
Retrospective analyzes of cruelty toward dogs and cats in the city of São Paulo
}

\author{
Elza Fernandes MARLET ${ }^{1}$; Paulo César MAIORKA ${ }^{2}$ \\ ${ }^{1}$ Academia de Polícia Civil de São Paulo, São Paulo-SP \\ ${ }^{2}$ Departamento de Patologia da Faculdade de Medicina Veterinária e Zootecnia da Universidade de São Paulo, São Paulo-SP
}

\begin{abstract}
Resumo
A Medicina Veterinária Legal é uma área em crescimento devido à demanda da sociedade na coibição dos crimes contra a fauna. No Brasil, pouco se conhece acerca da magnitude deste problema. Assim, o presente estudo propôsse a realizar um levantamento de casos em dois órgãos distintos que lidam com esta modalidade de crime em sua rotina de atendimento: o Serviço de Necropsia do Departamento de Patologia da FMVZ/USP e o Núcleo de Análise Instrumental do Instituto de Criminalística de São Paulo (NAI/IC). Este levantamento possibilitou a visualização do perfil quantitativo e qualitativo dos casos atendidos de maus tratos praticados contra cães e gatos, no período de 2003 a 2007. Constatou-se inicialmente que o número absoluto de casos de maus tratos em cães é maior que em gatos, porém, o confronto desses números absolutos com o tamanho da respectiva população atendida pelo Serviço de Necropsia da FMVZ/USP, revelou que os gatos são animais de eleição para as práticas de maus tratos. Constatou-se ainda que o sexo do animal não é fator relevante nessa eleição, mas a idade sim. Isso pode ser devido ao fato de animais de tenra idade serem mais indefesos que animais adultos. O tipo de maus tratos mais comumente praticado, tanto em cães como em gatos, é a intoxicação intencional e, os agentes tóxicos mais utilizados nestes casos são os carbamatos. Os resultados obtidos sugerem que a ampla utilização dos carbamatos decorre da facilidade com que podem ser adquiridos no comércio e fornecidos aos animais.
\end{abstract}

Palavras-chave: Maus tratos. Cães. Gatos. Medicina Veterinária Legal. Intoxicação. Aldicarb.

\begin{abstract}
The area of Legal Veterinary Medicine is growing due to the demand of society in restraining crimes against wildlife. In Brazil, little is known about the magnitude of this problem. Thus, this study set out to do a survey of cases in two separate bodies dealing with this type of crime in their routine care: the Autopsy Service, Department of Pathology FMVZ / USP and the Instrumental Analysis Center of the Institute Forensic São Paulo (NAI / IC). This survey enabled the visualization of a qualitative and quantitative profile of the seen cases of abuse committed against dogs and cats in the period 2003 to 2007 . The conclusions are: cats are more affected than dogs by the practice of maltreatment; there is no difference regarding sex, but age is a determinant factor, therefore young animals are predominantly maltreated; and the agents most commonly used to cause intentional poisoning are carbamates.
\end{abstract}

Keywords: Cruelty. Abuse. Dogs. Cats. Legal Veterinary Medicine Poisoning. Aldicarb.

\section{Introdução}

O Serviço de Necropsia do Departamento de Patologia da Faculdade de Medicina Veterinária e Zootecnia da Universidade de São Paulo (VPT/ FMVZ/USP) e o Núcleo de Análise Instrumental do Instituto de Criminalística de São Paulo (NAI/ IC) têm atendido casos de crimes contra a fauna. A Constituição da República Federativa do Brasil de 1988, assim como a legislação infraconstitucional, atribui grande importância aos crimes contra a fauna, pois deles podem decorrer desequilíbrio ao meio ambiente ${ }^{1}$, que viola o direito das presentes e futuras gerações ao meio ambiente ecologicamente equilibrado². A Lei de Crimes Ambientais, Lei no

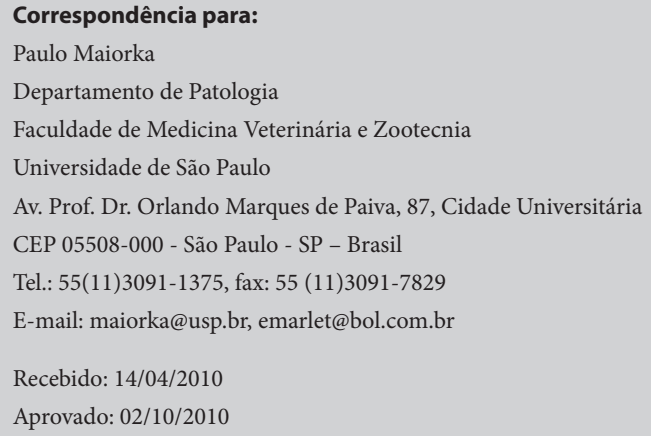


9.605 de 12 de fevereiro de 1998, tipifica os crimes contra a fauna e o crime de maus tratos aparece em seu artigo 32. Consideram-se maus tratos a violência, o ultraje ou o insulto que provoca sofrimento para o animal, ainda que não ocorram lesões físicas no mesmo ${ }^{3}$.

A importância desses crimes também é evidenciada por inúmeros trabalhos científicos que relacionam a prática de maus tratos contra animais com a ocorrência de violência doméstica ${ }^{4}$ e com a formação de personalidades criminosas $^{5}$, pois quando a violência praticada contra um animal não é coibida, ela pode ser entendida como normal e aceita pela sociedade, o que resulta no progresso da escalada da violência ${ }^{6}$. Por outro lado, existem trabalhos que demonstram que a relação saudável entre seres humanos e animais melhora o comportamento e a saúde mental e física do ser humano, o que contribui para a "sadia qualidade de vida"'.

A despeito da importância dos crimes de maus tratos praticados contra animais, pouco se conhece a respeito desse problema no $\mathrm{Brasil}^{8}$. O crime de maus tratos é subnotificado e sua investigação, que depende de provas, especialmente da prova pericial médico veterinária legal, é dificultada pela baixa disponibilidade de profissionais e de órgãos especializados trabalhando em sintonia com a Polícia Judiciária e a Justiça ${ }^{1}$.

A maioria dos estudos brasileiros encontrados dedica-se a um tipo específico de maus tratos, a intoxicação intencional ${ }^{9}$. No exterior, existem trabalhos ${ }^{10,11}$ voltados para as diferentes espécies de maus tratos. Assim, no Brasil, são necessários estudos que revelem a incidência das diferentes espécies do crime de maus tratos contra animais, bem como estudos que viabilizem a formação da prova pericial médico veterinária legal. Neste trabalho avaliou-se a incidência do crime de maus tratos contra cães e gatos atendidos em dois órgãos distintos: o Serviço de Necropsia do VPT/ FMVZ/USP e o NAI/IC, no período de 2003 a 2007.

\section{Material e Método}

Casos de crimes de maus tratos contra cães e gatos atendidos no VPT/FMVZ/USP

Foi realizado um levantamento da população de cães e gatos atendidos pelo Serviço de Necropsia VPT/FMVZ/USP, no período de 2003 a 2007, bem como a análise de todas as fichas de necropsia dessas espécies, a fim de se identificar indícios da prática do crime de maus tratos. Foram observados os seguintes parâmetros: história clínica, diagnóstico anátomo-patológico, causa mortis e moléstia principal. Uma vez selecionados os casos de interesse, foram coletadas informações relativas às características do animal. Estas informações foram registradas e usadas na elaboração de tabelas e gráficos que permitiram visualizar e avaliar a distribuição da frequência de casos de crimes contra a fauna de acordo com o ano, espécie, sexo, idade e tipo de energia vulnerante envolvida no delito.

Casos de crimes de maus tratos contra cães e gatos, atendidos no NAI/IC

O levantamento de casos de crimes de maus tratos contra cães e gatos atendidos pelo NAI/IC baseou-se no fato de que a intoxicação intencional de um animal ocorre, via de regra, por meio da disponibilização do agente tóxico misturado a uma porção de alimento, como carne moída ou peixe ${ }^{12}$.

Foram selecionados os casos atendidos pelo NAI/ IC, no período de 2003 a 2007, por meio de consulta aos livros de registro de casos, em que o objeto de exame era um alimento suspeito de conter um agente tóxico. Nessa ocasião, eram anotados o número de registro do caso, o número do laudo, o número do boletim de ocorrência e a Delegacia de Polícia requisitante do exame. Esses casos, então, foram separados em três grupos: (1)casos que se relacionavam a crimes contra animais; (2)casos que se relacionavam a crimes contra seres humanos; e (3) casos em que não foi possível identificar se o alvo do crime era um animal ou um ser humano. Este terceiro grupo dfoi denominado 
casos indeterminados e contém casos relacionados a animais que não puderam ser contabilizados e acrescentados ao grupo de casos de crimes contra animais. Com isso, há uma certeza do número mínimo de crimes contra animais atendidos pelo NAI, mas não do número máximo desses casos. Mas, mesmo sendo difuso o limite superior do grupo de casos de crimes contra animais, pode-se inferir a tendência demonstrada pelos dados.

Uma vez definido o grupo de casos de crimes contra animais, de cada caso foram coletadas informações relativas à sua identificação, espécie animal envolvida, agente tóxico identificado pelo exame pericial e outras observações. Estas informações foram registradas e usadas na elaboração de tabelas e gráficos que permitiram visualizar a distribuição anual e a proporção dos casos referentes a crimes contra animais em relação ao total de casos atendidos pelo NAI; a proporção de casos envolvendo animais das espécies canina e felina; e quais os agentes tóxicos utilizados.

\section{Resultados e Discussão}

Os resultados obtidos com o levantamento de casos procedido no VPT/FMVZ/USP e no NAI/IC revelaram informações quanto à espécie, sexo, idade e tipo de energia vulnerante envolvida na prática de maus tratos.

No período compreendido entre 2003 e 2007, foi realizado um total de 1.950 necropsias no VPT/ FMVZ/USP, em diferentes espécies animais. Deste total (1.950), 861 (44\%) necropsias foram realizadas em cães, 229 (12\%) em gatos e 860 (44\%) em animais de outras espécies (Figura 1).

Os cães representam a maioria dos casos atendidos nos anos 2003, 2004 e 2005 (Figura 2); contudo, a partir de 2006, o total de casos atendidos de outras espécies, isto é, de espécies diferentes das espécies canina e felina, supera os da espécie canina. E, enquanto o número de casos de cães e gatos permanece relativamente estável, o número de casos de outras espécies aumenta quase três vezes (2,87 vezes) entre 2003 (96 casos) e 2007 (276 casos). Foi constatado assim, que o

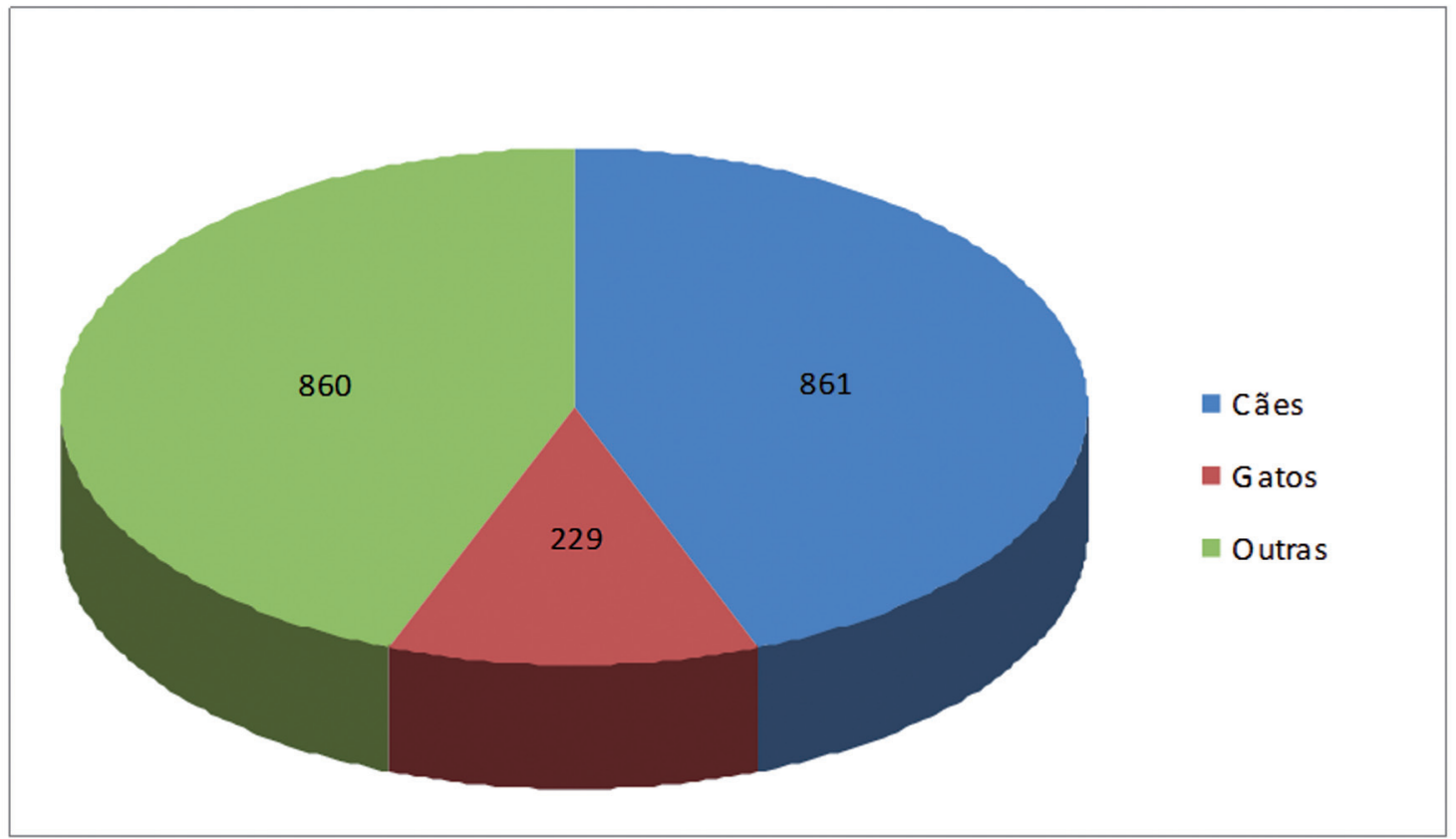

Figura 1 - Casos atendidos pelo Serviço de Necropsia do Departamento de Patologia da Faculdade de Medicina Veterinária e Zootecnia da Universidade de São Paulo, segundo a espécie animal submetida a exame de necropsia, no período de 2003 a 2007 
aumento do número total de necropsias realizadas entre 2003 e 2007 foi devido ao aumento do número de necropsias realizadas em animais de espécies diferentes das espécies canina e felina, espécies domésticas ou silvestres (Figura 2).

O conjunto de cães submetidos a exame necroscópico no VPT/FMVZ/USP é maior que o conjunto de gatos submetidos a exame de necropsia, em todos os anos (Figura 2). Este resultado deve-se ao fato de os cães serem mais populares como animais de companhia ${ }^{13}$ que os gatos. Apesar da popularidade dos cães, Garcia $^{14}$ alerta para o fato de que ocorreu um aumento de cerca de $10 \%$ no número de lares que têm pelo menos um gato, entre 2005 e 2008, devido à facilidade com que esses animais se adaptam em casas pequenas e apartamentos.

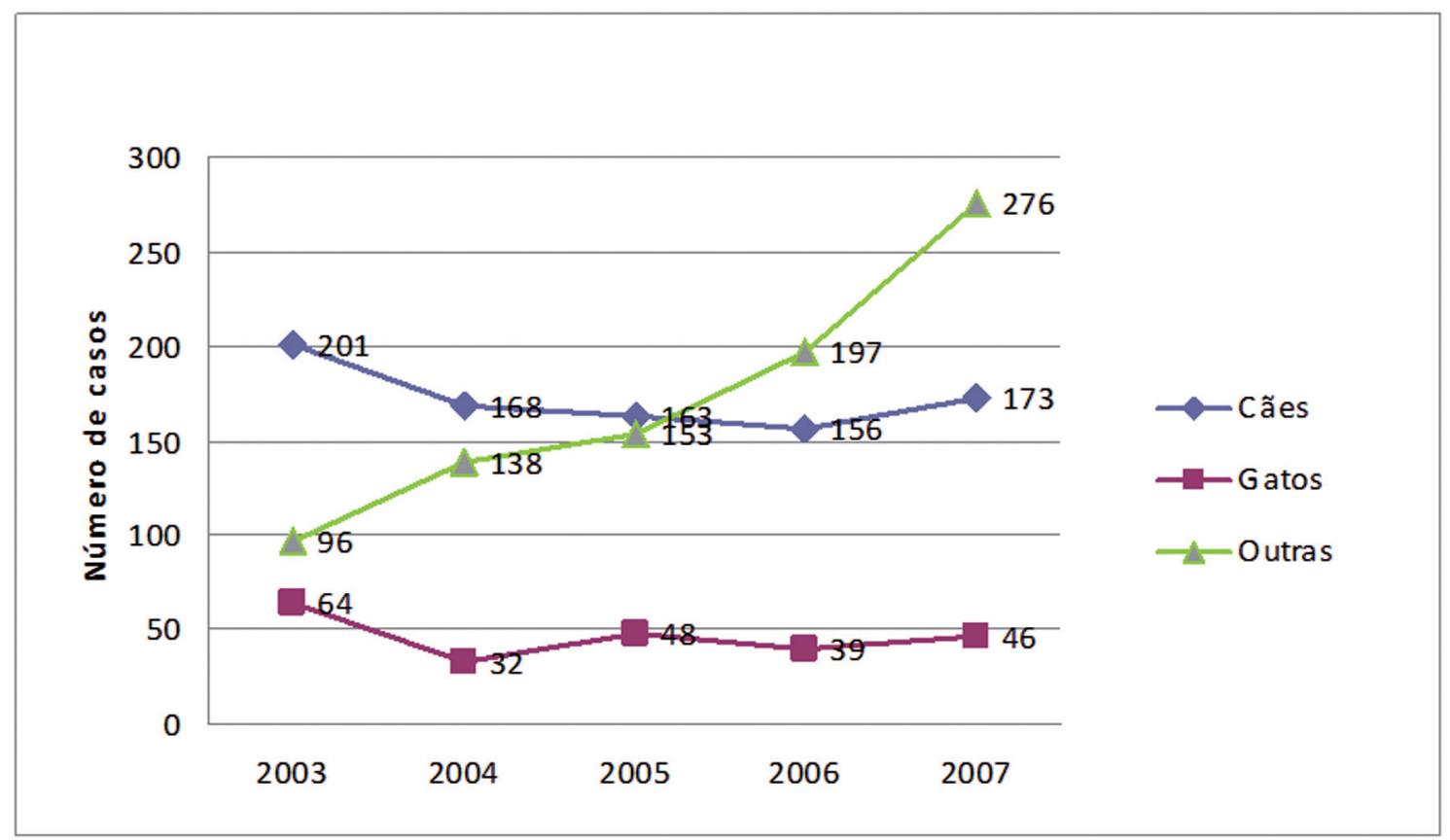

Figura 2 - Casos atendidos pelo Serviço de Necropsia do Departamento de Patologia da Faculdade de Medicina Veterinária e Zootecnia da Universidade de São Paulo, segundo o ano e a espécie animal submetida a exame de necropsia, no período de 2003 a 2007

$\mathrm{O}$ número total de casos atendidos pelo VPT/ FMVZ/USP (Tabela 1) é maior em cães (861) do que em gatos (229), em todos os anos (2003 a 2007). Porém o número percentual desses casos é maior em gatos (34\%) que em cães (11\%) (Tabela 1). Contatou-se assim, que a proporção de casos de maus tratos em relação ao tamanho da respectiva população é maior em gatos que em cães. Isto sugere que os gatos são animais de eleição para as práticas de maus tratos.

A predominância do número percentual de casos de maus tratos em gatos está relacionada ao fato de eles possuírem maior facilidade de acesso a rua e casas vizinhas, o que os torna mais susceptíveis às ações humanas que configuram práticas de maus tratos. $\mathrm{O}$ fato dos gatos tenderem a se isolar quando estão doentes, pode mascarar um número ainda maior de casos de maus tratos contra eles.

Os Boletins de Ocorrência (BO’s) referentes aos casos de crimes contra animais levantados junto ao NAI/IC relatam histórias que nos ajudam a compreender a motivação e as circunstâncias em que ocorrem as práticas de maus tratos em animais. Os BO's 
Tabela 1 - Distribuição* dos casos de maus tratos em cães e gatos atendidos pelo Serviço de Necropsia da FMVZ/USP, no período de 2003 a 2007, em relação ao total de casos submetidos a exame de necropsia

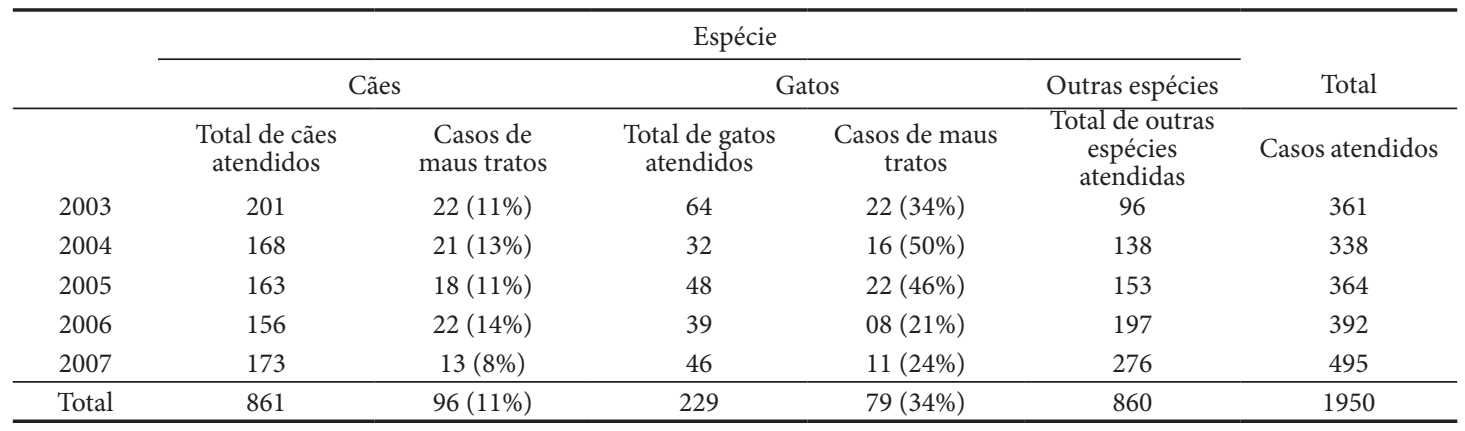

* Distribuição em número absoluto e, entre parênteses, em porcentagem.

relatam vários casos em que um vizinho, desgostoso com as constantes incursões de um felino em seu quintal ou em áreas comuns de condomínios, disponibiliza ao animal uma substância tóxica misturada a um alimento. Nestes casos, após ingerir o agente tóxico o gato pode ir a óbito em via pública, nas imediações do lugar em que ele ingeriu o agente tóxico ou na casa em que vivia. Em relação aos caninos, os BO’s indicam que muitas vezes os cães são intoxicados no interior da residência em que vivem por vizinhos que se incomodam com os constantes latidos, ou mesmo para cumprir uma ameaça anteriormente feita em função de uma desavença; também não são raros casos em que marginais, com o propósito de cometer crimes contra o patrimônio, intoxicam cães objetivando ingressar no interior de um imóvel. Nestes casos, em que uma substância tóxica é lançada no local em que o animal vive ou frequenta, misturada a um alimento, o proprietário pode encontrar, além do animal morto ou moribundo, uma porção de alimento suspeito de conter o agente tóxico. Sendo assim, ao ser notificado do crime, o Delegado de Polícia pode requisitar exame pericial no local do fato, no alimento suspeito e no corpo do animal, a fim de estabelecer a dinâmica da ocorrência e sua autoria. Os BO's também revelam que cães e gatos que vivem ou frequentam as vias públicas estão sujeitos a outras práticas de maus tratos, tais como atropelamento ou espancamento.

A figura 3 mostra que entre os casos de maus tratos praticados contra cães (96) atendidos pelo VPT/ FMVZ/USP no período de 2003 a 2007, 53\% (51) dos casos eram de machos, 44\% (42) eram de fêmeas e 3\% (3) dos casos não apresentavam indicação de sexo. Entre os casos de maus tratos praticados contra gatos (79), 48\% (38) eram machos e 52\% (41) eram fêmeas. Os BO's, em geral, não indicam o sexo ou a idade do animal afetado, mas apenas a espécie. A ligeira predominância de cães machos (53\%) e de gatos fêmeas (52\%) no total de casos de crimes de maus tratos atendidos pelo VPT/FMVZ/USP (Tabela 2) é compatível com a predominância de cães machos (53\%) e de felinos fêmeas (57\%) nesta região ${ }^{15}$, indicando que o sexo do cão ou do gato não é fator relevante na escolha do animal a ser agredido com maus tratos.

Munro e Munro ${ }^{4}$ obtiveram resultados semelhantes em relação aos gatos, no entanto, em relação aos cães, encontraram resultado diferente ao comparar a população de cães machos afetados por maus tratos (70\%) com a população de cães machos na população em geral (50\%). Segundo Munro e Munro ${ }^{4}$ é possível que proprietários potencialmente violentos prefiram possuir cães machos, ou ainda, que cães machos sejam 


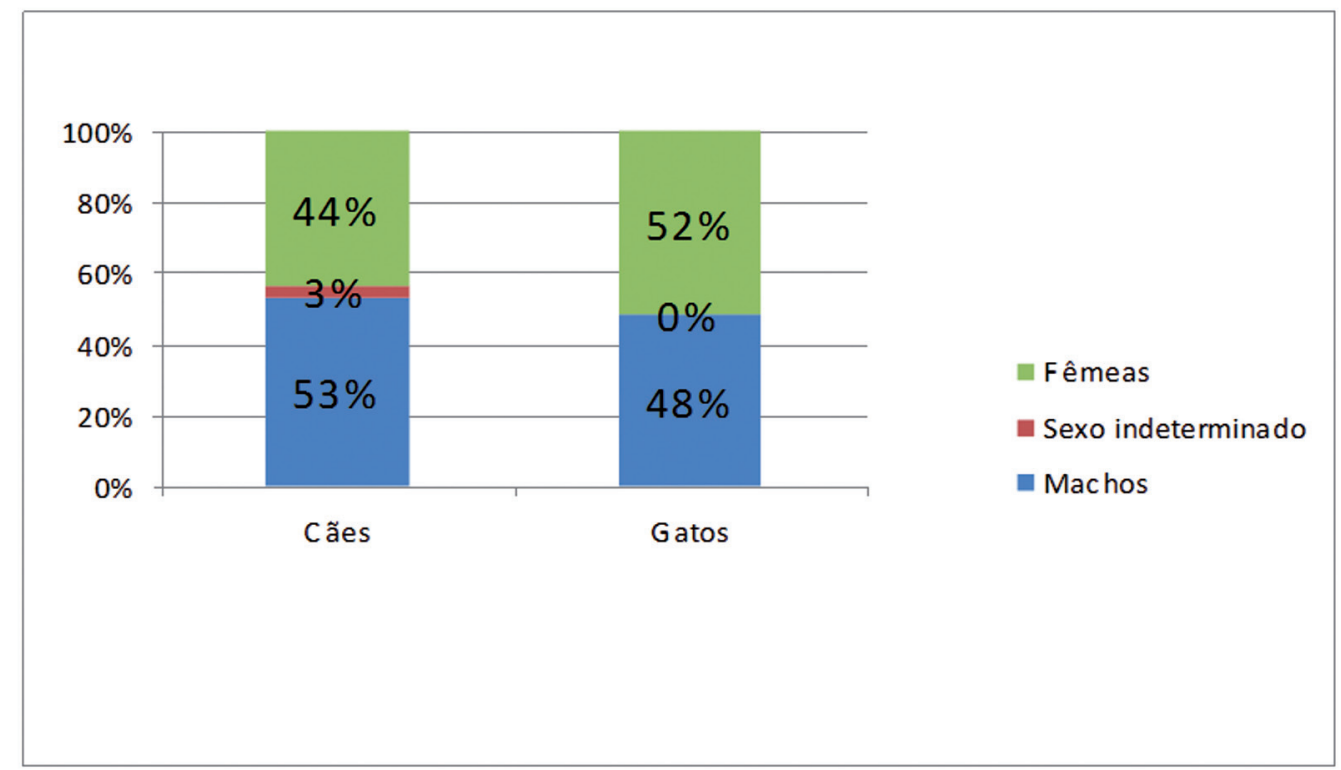

Figura 3 - Distribuição* dos casos de maus tratos praticados contra cães e gatos atendidos pelo Serviço de Necropsia do Departamento de Patologia da Faculdade de Medicina Veterinária e Zootecnia da Universidade de São Paulo, no período de 2003 a 2007, segundo a espécie e o sexo. * Distribuição em número percentual

Tabela 2 - Distribuição* dos casos de crimes contra fauna atendidos pelo NAI/IC, segundo o ano, no período de 2003 a 2007

\begin{tabular}{ccccc}
\hline \multicolumn{5}{c}{ Casos atendidos pelo NAI/IC } \\
\hline & $\begin{array}{c}\text { Crimes contra } \\
\text { animais }\end{array}$ & $\begin{array}{c}\text { Casos } \\
\text { indeterminados }\end{array}$ & $\begin{array}{c}\text { Crimes contra } \\
\text { seres humanos }\end{array}$ & Total \\
\hline 2003 & $49(11 \%)$ & $13(3 \%)$ & $389(86 \%)$ & $451(100 \%)$ \\
2004 & $79(12 \%)$ & $24(4 \%)$ & $533(84 \%)$ & $636(100 \%)$ \\
2005 & $102(14 \%)$ & $35(5 \%)$ & $608(82 \%)$ & $745(100 \%)$ \\
2006 & $65(9 \%)$ & $32(4 \%)$ & $643(87 \%)$ & $740(100 \%)$ \\
2007 & $57(7 \%)$ & $45(5 \%)$ & $736(88 \%)$ & $838(100 \%)$ \\
\hline Total & $352(10 \%)$ & $149(4 \%)$ & $2909(85 \%)$ & $3410(100 \%)$ \\
\hline
\end{tabular}

* Distribuição em número absoluto e, entre parênteses, em porcentagem.

mais difíceis de controlar, ou que sejam mais agressivos que as fêmeas, podendo desencadear a violência de seus proprietários. A diferença de resultados obtidos por Munro e Munro ${ }^{4}$ e o presente trabalho pode ser devida ao fato de a pesquisa destes autores ter sido realizada em cães levados para atendimento em clínicas e hospitais veterinários no Reino Unido, e aborda a violência de pessoas em relação a seus próprios animais. Já a presente pesquisa considerou casos em que o animal, vindo a óbito, foi atendido pelo Serviço de
Necropsia do VPT/FMVZ/USP, e a violência dirigida a eles nestes casos não partiu do proprietário do animal. Assim, pode-se entender que quando alguém elege um animal que não é seu para praticar maus tratos, o sexo do animal eleito não é relevante.

Em relação à idade, a figura 4 mostra que os casos de maus tratos praticados contra cães (96) atendidos pelo VPT/FMVZ/USP estão mais concentrados na faixa de 1,1 a 5 anos (42\%); em seguida figuram cães mais velhos, na faixa de 5,1 a 10 anos (23\%) e os fi- 


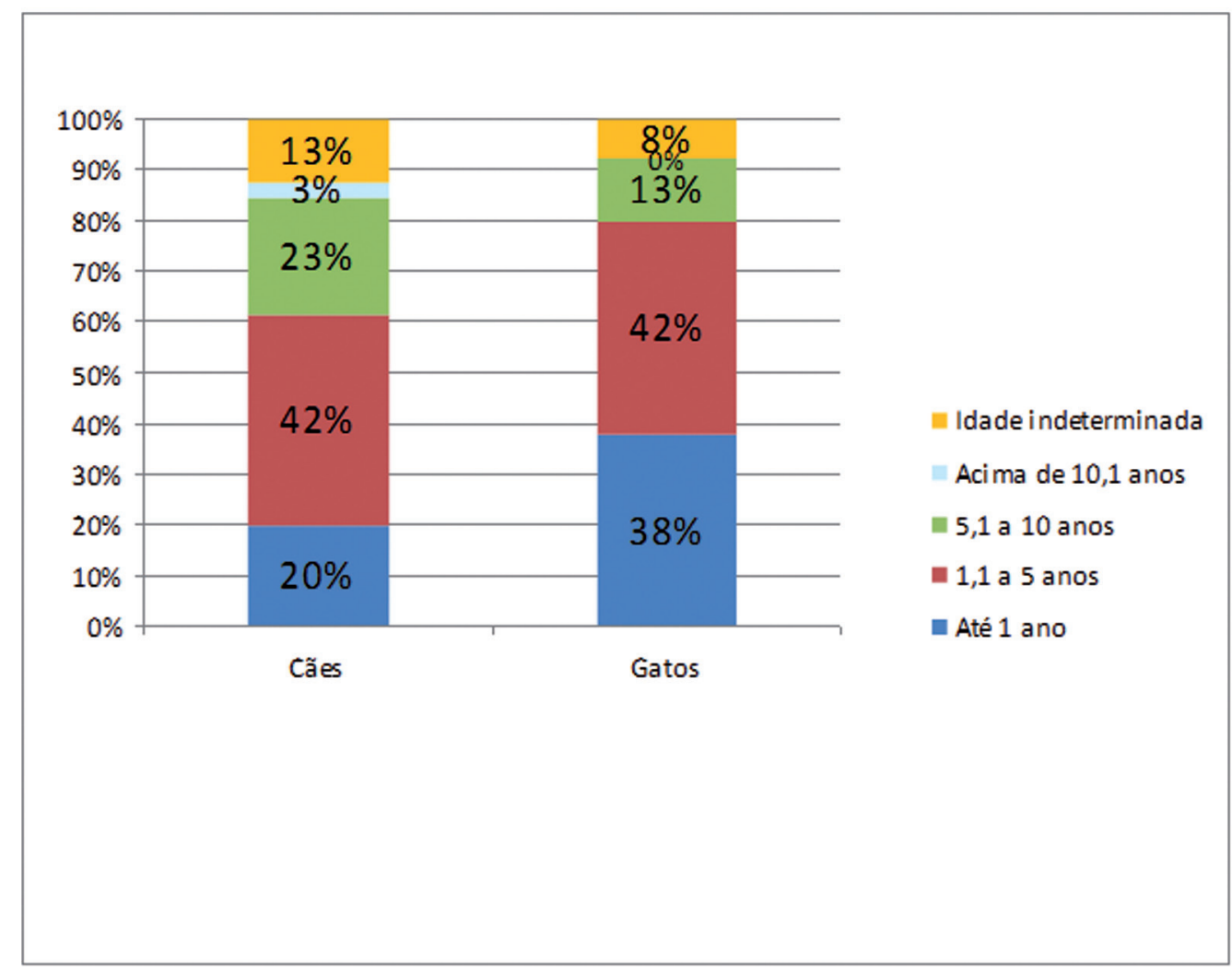

Figura 4 - Distribuição* dos casos de crimes de maus tratos praticados contra cães e gatos atendidos pelo Departamento de Patologia da Faculdade de Medicina Veterinária e Zootecnia da Universidade de São Paulo, no período de 2003 a 2007, segundo a espécie e a idade. * Distribuição em números percentuais

lhotes com até um ano (20\%); mais raros são os casos em cães acima de 10 anos de idade (3\%). Contudo, a comparação da porcentagem de cães com menos de um ano que sofreram maus tratos $(20 \%)$ com a porcentagem de cães nessa faixa etária em São Paulo $(11 \%)^{15}$ evidencia que cães com até um ano de idade estão muito sujeitos a práticas de maus tratos.

Na população de gatos atendidos pelo VPT/FMVZ/ USP (Figura 4) entre 2003 e 2007, a faixa etária mais atingida é a de 1,1 a 5 anos (42\%), porém gatos mais jovens, até 1 ano, também são muito afetados (38\%) e, em terceiro, lugar figuram gatos na faixa entre 5,1 e 10 anos de idade (13\%). Não foram detectados casos de maus tratos em gatos com mais de 10 anos de idade (Figura 4). A comparação destes resultados com o perfil etário da população felina em São Paulo ${ }^{15}$ indica que felinos com até um ano de idade são os mais afetados pela prática de maus tratos.

Interessante mencionar ainda que na população humana, $80 \%$ dos menores maltratados têm menos de três anos e 40\% deles têm menos de seis meses de idade $^{16}$. Esta informação reforça a ideia de que a tenra idade, tanto em animais como em seres humanos, torna a vítima muito indefesa em relação ao seu agressor.

O tipo de energia vulnerante mais utilizado na prática de maus tratos contra animais é a química, ela representa $71 \%$ dos casos de maus tratos em cães e $73 \%$ em gatos atendidos pelo VPT/FMVZ/USP (Tabela 3). Isso pode ser devido à facilidade de aquisição do agente tóxico, bem como à facilidade de sua administração misturada ao alimento ${ }^{13}$. $\mathrm{O}$ agente químico mais utilizado nestes casos é o carbamato ${ }^{8}$, ele respon- 
Tabela 3 - Distribuição* dos casos de crimes de maus tratos contra cães e gatos atendidos pelo Serviço de Necropsia do Departamento de Patologia da Faculdade de Medicina Veterinária e Zootecnia da Universidade de São Paulo, segundo o ano e o tipo de energia vulnerante, no período de 2003 a 2007

\begin{tabular}{|c|c|c|c|c|c|c|c|c|c|}
\hline & \multicolumn{8}{|c|}{ Espécie } & \multirow{3}{*}{ Total } \\
\hline & \multicolumn{4}{|c|}{ Cães } & \multicolumn{4}{|c|}{ Gatos } & \\
\hline & $\begin{array}{c}\text { Traumatismo } \\
\text { Energia } \\
\text { mecânica }\end{array}$ & $\begin{array}{l}\text { Intoxicação } \\
\text { Energia } \\
\text { química }\end{array}$ & $\begin{array}{c}\text { Estresse } \\
\text { Energia } \\
\text { biodinâmica }\end{array}$ & Total & $\begin{array}{c}\text { Traumatismo } \\
\text { Energia } \\
\text { mecânica }\end{array}$ & $\begin{array}{c}\text { Intoxicação } \\
\text { Energia } \\
\text { química }\end{array}$ & $\begin{array}{c}\text { Estresse } \\
\text { Energia } \\
\text { biodinâminca }\end{array}$ & Total & \\
\hline 2003 & $\begin{array}{c}4 \\
(18 \%)\end{array}$ & $\begin{array}{c}17 \\
(77 \%)\end{array}$ & $\begin{array}{c}1 \\
(5 \%)\end{array}$ & $\begin{array}{c}22 \\
(50 \%)\end{array}$ & $\begin{array}{c}5 \\
(23 \%)\end{array}$ & $\begin{array}{c}15 \\
(68 \%)\end{array}$ & $\begin{array}{c}2 \\
(9 \%)\end{array}$ & $\begin{array}{c}22 \\
(50 \%)\end{array}$ & $\begin{array}{c}44 \\
(100 \%)\end{array}$ \\
\hline 2004 & $\begin{array}{c}7 \\
(33 \%)\end{array}$ & $\begin{array}{c}13 \\
(62 \%)\end{array}$ & $\begin{array}{c}1 \\
(5 \%)\end{array}$ & $\begin{array}{c}21 \\
(57 \%)\end{array}$ & $\begin{array}{c}3 \\
(19 \%)\end{array}$ & $\begin{array}{c}13 \\
(81 \%)\end{array}$ & $\begin{array}{c}0 \\
(0 \%)\end{array}$ & $\begin{array}{c}16 \\
(43 \%)\end{array}$ & $\begin{array}{c}37 \\
(100 \%)\end{array}$ \\
\hline 2005 & $\begin{array}{c}3 \\
(17 \%)\end{array}$ & $\begin{array}{c}15 \\
(83 \%)\end{array}$ & $\begin{array}{c}0 \\
(0 \%)\end{array}$ & $\begin{array}{c}18 \\
(45 \%)\end{array}$ & $\begin{array}{c}7 \\
(32 \%)\end{array}$ & $\begin{array}{c}15 \\
(68 \%)\end{array}$ & $\begin{array}{c}0 \\
(0 \%)\end{array}$ & $\begin{array}{c}22 \\
(55 \%)\end{array}$ & $\begin{array}{c}40 \\
(100 \%)\end{array}$ \\
\hline 2006 & $\begin{array}{c}5 \\
(23 \%)\end{array}$ & $\begin{array}{c}15 \\
(68 \%)\end{array}$ & $\begin{array}{c}2 \\
(9 \%)\end{array}$ & $\begin{array}{c}22 \\
(73 \%)\end{array}$ & $\begin{array}{c}2 \\
(25 \%)\end{array}$ & $\begin{array}{c}6 \\
(75 \%)\end{array}$ & $\begin{array}{c}0 \\
(0 \%)\end{array}$ & $\begin{array}{c}08 \\
(27 \%)\end{array}$ & $\begin{array}{c}30 \\
(100 \%)\end{array}$ \\
\hline 2007 & $\begin{array}{c}1 \\
(8 \%)\end{array}$ & $\begin{array}{c}8 \\
(62 \%)\end{array}$ & $\begin{array}{c}4 \\
(31 \%)\end{array}$ & $\begin{array}{c}13 \\
(54 \%)\end{array}$ & $\begin{array}{c}2 \\
(18 \%)\end{array}$ & $\begin{array}{c}9 \\
(82 \%)\end{array}$ & $\begin{array}{c}0 \\
(0 \%)\end{array}$ & $\begin{array}{c}11 \\
(46 \%)\end{array}$ & $\begin{array}{c}24 \\
(100 \%)\end{array}$ \\
\hline Total & $\begin{array}{c}20 \\
(21 \%)\end{array}$ & $\begin{array}{c}68 \\
(71 \%)\end{array}$ & $\begin{array}{c}8 \\
(8 \%)\end{array}$ & $\begin{array}{c}96 \\
(55 \%)\end{array}$ & $\begin{array}{c}19 \\
(24 \%)\end{array}$ & $\begin{array}{c}58 \\
(73 \%)\end{array}$ & $\begin{array}{c}2 \\
(3 \%)\end{array}$ & $\begin{array}{c}79 \\
(45 \%)\end{array}$ & $\begin{array}{c}175 \\
(100 \%)\end{array}$ \\
\hline
\end{tabular}

* Distribuição em número absoluto e, entre parênteses, em porcentagem.

Tabela 4 - Distribuição dos casos confirmados de crimes contra a fauna atendidos pelo NAI/IC, no período de 2003 a 2007, segundo o ano e a espécie animal envolvida, em número absoluto e porcentagem

\begin{tabular}{cccccc}
\hline \multicolumn{7}{c}{ Casos de crimes contra animais atendidos pelo NAI/IC } \\
\hline 2003 & Cães & Gatos & Outras espécies & Espécie indeterminada* $^{*}$ Total $^{*}$ \\
2004 & $13(27 \%)$ & $3(6 \%)$ & $1(2 \%)$ & $32(65 \%)$ & 49 \\
2005 & $38(48 \%)$ & $13(16 \%)$ & $7(9 \%)$ & $21(27 \%)$ & 79 \\
2006 & $44(43 \%)$ & $24(24 \%)$ & $5(5 \%)$ & $29(28 \%)$ & 102 \\
2007 & $26(40 \%)$ & $11(17 \%)$ & $3(5 \%)$ & $25(38 \%)$ & 65 \\
\hline Total & $27(47 \%)$ & $4(7 \%)$ & $4(7 \%)$ & $22(39 \%)$ & 57 \\
\hline
\end{tabular}

*A indeterminação da espécie deveu-se ao fato de não ter sido possível consultar o boletim de ocorrência, ou de a espécie animal envolvida não ser mencionada no boletim de ocorrência.

de por pelo menos $59 \%$ dos casos de crimes contra animais atendidos pelo NAI/IC (Tabela 5) ${ }^{17}$. Segundo Xavier, Righi e Spinosa ${ }^{18}$ o aldicarb é utilizado em $89,0 \%$ dos casos de intoxicação em cães e $94,4 \%$ dos casos de intoxicação em gatos.

A energia mecânica representa o segundo tipo de maus tratos mais frequente (Tabela 2): $21 \%$ dos casos de maus tratos em cães e $24 \%$ em gatos atendidos pelo VPT/FMVZ/USP. No entanto, deve-se lembrar que os traumatismos podem ser praticados por pessoas que vivem com o animal e muitas vezes estes casos não são notificados, levados a tratamento em clínicas ve- terinárias, ou mesmo para exame necroscópico, fato que pode mascarar uma casuística maior que a revelada no presente estudo ${ }^{4,6}$.

A energia biodinâminca atingiu $8 \%$ dos cães e $3 \%$ dos gatos atendidos pelo Serviço de Necropsia da FMVZ/ USP. Estes casos têm histórico ligado a situações estressantes para o animal, tais como banho em pet shop.

$\mathrm{O}$ confronto entre os resultados obtidos junto ao NAI/IC (Tabelas 3, 4 e 5) e os resultados obtidos junto ao VPT/FMVZ/USP (Tabela 2) revelou importante informação. Enquanto os resultados obtidos junto ao NAI mostram um aumento progressivo no número 
Tabela 5 - Distribuição* dos casos confirmados de crimes contra a fauna, atendidos pelo NAI/IC, no período de 2003 a 2007, segundo o ano e o resultado dos exames periciais elaborados

\begin{tabular}{|c|c|c|c|c|c|c|c|}
\hline \multicolumn{8}{|c|}{ Casos de crimes contra animais atendidos pelo NAI/IC } \\
\hline \multicolumn{8}{|c|}{ Resultado dos exames periciais } \\
\hline & Negativo & Carbamatos & $\begin{array}{l}\text { Organo- } \\
\text { fosforados }\end{array}$ & $\begin{array}{l}\text { Organo- } \\
\text { clorados }\end{array}$ & Cumarínicos & outros & Total \\
\hline 2003 & $19(39 \%)$ & $27(55 \%)$ & $1(2 \%)$ & $0(0 \%)$ & $0(0 \%)$ & $2(4 \%)$ & 49 \\
\hline 2004 & $24(30 \%)$ & $45(57 \%)$ & $2(3 \%)$ & $1(1 \%)$ & $4(5 \%)$ & $3(4 \%)$ & 79 \\
\hline 2005 & $26(25 \%)$ & $71(70 \%)$ & $1(1 \%)$ & $1(1 \%)$ & $2(2 \%)$ & $1(1 \%)$ & 102 \\
\hline 2006 & $23(35 \%)$ & $36(55 \%)$ & $1(2 \%)$ & $0(0 \%)$ & $3(5 \%)$ & $2(3 \%)$ & 65 \\
\hline 2007 & $20(35 \%)$ & $27(47 \%)$ & $1(2 \%)$ & $0(0 \%)$ & $6(11 \%)$ & $3(5 \%)$ & 57 \\
\hline Total & $112(32 \%)$ & $206(59 \%)$ & $6(2 \%)$ & $2(1 \%)$ & $15(4 \%)$ & $11(3 \%)$ & 352 \\
\hline
\end{tabular}

* Distribuição em número absoluto e, entre parênteses, em porcentagem.

de casos de crimes contra animais (Tabelas 3 e 4), bem como do número de resultados positivos para os carbamatos (Tabela 5) entre 2003 e 2005, seguido de forte redução nos anos seguintes, 2006 e 2007 (Tabela 5); os resultados obtidos junto ao VPT/FMVZ/USP referentes aos casos em que foi utilizada energia vulnerante do tipo química (Tabela 2), mostram uma variação menor nos números nos primeiros anos, porém seguidos da mesma forte redução em 2007 para cães, e em 2006/2007 para gatos. Esta comparação pode indicar que houve diminuição na disponibilidade de agentes químicos do tipo carbamato no comércio, o que dificulta a prática dessa modalidade de crime de maus tratos. Sendo assim pode-se inferir que o aumento do número de casos positivos para cumarínicos e outros agentes químicos, nos anos 2006 e 2007 (Tabela 5) pode ser decorrente da busca por um produto alternativo para a prática do crime de maus tratos.

\section{Referências}

1. ALMEIDA, J. R. Perícia ambiental judicial e securitária: impacto, dano e passivo ambiental. Rio de Janeiro: Thex, 2006. $501 \mathrm{p}$.

2. FIORILLO, C. A. P. Curso de direito ambiental brasileiro. 7. ed. São Paulo: Saraiva, 2006. 532 p

3. LEVAI, L. F. Direito dos animais. 2. ed. Campos do Jordão: Mantiqueira, 2004. 159 p.

4. MUNRO, R.; MUNRO, H. M. C. Animal abuse and unlawful

\section{Conclusões}

Os resultados obtidos revelaram diversas informações acerca da ocorrência dos crimes de maus tratos em animais em São Paulo: a espécie felina é mais sujeita à prática de maus tratos que a espécie canina; o sexo do cão ou do gato não é fator relevante na eleição do animal como alvo de maus tratos, quando a pessoa que os pratica não é seu proprietário; a faixa etária mais afetada pela prática de maus tratos nas populações canina e felina é a de animais com até um ano de idade; a energia vulnerante mais comumente empregada na prática de crimes contra a fauna é a química (intoxicação de animais) e os carbamatos são os agentes tóxicos mais utilizados para a prática dos crimes de maus tratos contra cães e gatos. O controle adequado do comércio de carbamatos e de outros agentes químicos, tal como os cumarínicos, pode reduzir a ocorrência de crimes contra a fauna.

killing: forensic veterinary pathology. China: Saunders, 2008. $106 \mathrm{p}$.

5. FARACO, C. B.; SEMINOTTI, N. A crueldade com animais: como identificar seus sinais? O Médico Veterinário e a prevenção da violência doméstica. Revista do Conselho Federal de Medicina Veterinária, ano 12, n. 37, p. 66-71, 2006.

6. MERCK, M. D. Veterinary forensics: animal cruelty investigationns. Iowa: Melinda Merck, 2007. 327 p. 
7. ANDERLINI, G. P. O. S.; ANDERLINI, G. A. Benefícios do envolvimento do animal de companhia (cão e gato), na terapia, socialização e bem estar das pessoas e o papel do Médico Veterinário. Revista Conselho Federal de Medicina Veterinária, ano 13, n. 41, p. 70-75, 2007.

8. XAVIER, F. G.; RIGHI, D. A.; SPINOSA, H. S. Toxicologia do praguicida aldicarb ("chumbinho"): aspectos gerais, clínicos e terapêuticos em cães e gatos. Ciência Rural, v. 37, n. 4, p. 1206$1211,2007$.

9. BURINI, C. H. P.; LAUFER AMORIM, R.; VASSILIEFF, I.; BANDARRA, E. P. Estudo retrospectivo de envenenamentos intencionais em gatos na região de Botucatu, estado de São Paulo. In: ENAPAVE - ENCONTRO NACIONAL DE PATOLOGIA VETERINÁRIA, 11, 2003, Botucatu. Anais... Botucatu: FMVZ, UNESP, 2003.

10.MUNRO, H. M.; THRUSFIELD, M. V. 'Battered pets': nonaccidental physical injuries found in dogs and cats. Journal of Small Animal Practice, v. 42, n. 6, p. 279-290, 2001.

11.MUNRO, H. M.; THRUSFIELD, M. V. 'Battered pets': features that raise suspicion of non-accidental injury. Journal of Small Animal Practice, v. 42, n. 6, p. 218-226, 2001.

12.SPINOSA, H. S.; GÓRNIAK, S. L.; PALERMO-NETO, J. Toxicologia aplicada à medicina veterinária. Barueri: Manole, 2008. 942 p.

13.XAVIER, F. G. Intoxicação por aldicarb ("chumbinho"): I. Estudo das alterações "post mortem" microscópicas em cães e gatos - II. Avaliação dos efeitos tóxicos agudos em camundongos. 2008. 201 f. Tese (Doutorado em Medicina Veterinária) - Faculdade de Medicina Veterinária e Zootecnia, Universidade de São Paulo, São Paulo, 2008.

14.GARCIA, R. C. M. Estudo da dinâmica populacional canina e felina e avaliação de ações para o equilíbrio dessas populações em áreas da cidade de São Paulo, SP, Brasil. 2009. 265 f. Tese (Doutorado em Medicina Veterinária) - Faculdade de Medicina Veterinária e Zootecnia, Universidade de São Paulo, São Paulo, 2009.

15.MAGNABOSCO, C. População domiciliada de cães e gatos no Município de São Paulo: perfil obtido através de um inquérito multicêntrico. 2006. 110 p. Dissertação (Mestrado) - Faculdade de Saúde Pública, Universidade de São Paulo, São Paulo, 2006.

16. FRANCA, G. V. Medicina legal. 7. ed. Rio de Janeiro: Guanabara Koogan, 2008. 629 p.

17.PEDROZO, M. F. M.; SILVA, A. P.; CARVALHO, D. G.; SILVA, E. S.; BARON, L. Prevalência de aldicarb em ocorrências registradas nos Núcleos de Análise Instrumental (NAI/ IC-SP) e de Toxicologia Forense (NTF/IML-SP) no ano de 2005. Revista Brasileira de Toxicologia, v. 20, p. 291, 2007. Suplemento, 3. Trabalho apresentado no XV Congresso Brasileiro de Toxicologia, 2007.

18.XAVIER, F. G.; RIGHI, D. A.; SPINOSA, H. S. Fatal poisoning in dogs and cats - 16 - year report in a veterinary pathology service. Brazilian Journal of Veterinary Research and Animal Scienci, v. 44, n. 4, p. 304-309, 2007. 